\title{
Experimental warming drives a seasonal shift of ecosystem carbon exchange in
} Tibetan alpine meadow

Juntao Zhu ${ }^{1}$, Yangjian Zhang ${ }^{1,2,3^{*}}$, Lin Jiang ${ }^{4}$

\begin{abstract}
The effects of warming-shifted plant phenology on ecosystem carbon (C) cycling have received increasing attention in recent years. However, there is a lack of evidence and mechanistic understanding of how warming-shifted plant phenology influences ecosystem C cycling. In this study, we conducted a field experiment to investigate the effects of warming on phenology and ecosystem C exchange in a Tibetan alpine meadow during the 2014 and 2015 growing seasons. Our results indicated that warming led to later green-up in spring by aggravating water limitation but little change in autumn phenology, resulting in shortened growing season length. Interestingly, we found warming caused a seasonal shift of ecosystem $\mathrm{C}$ exchange. During the early summer monsoon, ecosystem $\mathrm{C}$ uptake was suppressed by warming due to the delay of phenological development. However, warming accelerated ecosystem C uptake and promoted ecosystem C uptake under ample water conditions during the late summer monsoon. As a result, although warming shortened the growing season length, it had no significant effects on gross primary production (GPP) and net ecosystem production (NEP). Our results will improve our understanding of the mechanisms of how warming-shifted plant phenology influences ecosystem C cycling in semiarid alpine ecosystems.
\end{abstract}




\section{Introduction}

The global mean air temperature has increased continuously since the industrial revolution (IPCC 2014), and the rising temperatures can impact ecosystem $\mathrm{CO}_{2}$ exchanges, potentially causing both positive and negative feedbacks to future climates (Luo, 2007; Brient and Bony, 2013). Alpine and arctic ecosystems are believed to be more sensitive to warming because they are experiencing higher than average rates of temperature increases under global climate change (Root et al., 2003; IPCC, 2007). For example, historical climate records show that the Tibetan Plateau has experienced substantial warming in recent decades (i.e., $0.32^{\circ} \mathrm{C}$ per decade, Liu and Chen, 2000), and this trend is projected to continue for the future.

The coupled climate- $\mathrm{C}$ models predict a positive feedback between terrestrial $\mathrm{C}$ cycle and climate warming, primarily due to the increased $\mathrm{C}$ release under warming (Friedlingstein et al., 2006). Recent meta-analyses of ecosystem carbon cycle response to warming have also shown that warming increased ecosystem C release (Lu et al., 2013; Wang et al., 2014). However, experiments have shown inconsistent results, with increase (Niu et al., 2013), decrease (Fu et al., 2013; Pendall et al., 2013) or little change (Xia et al., 2009; Chen et al., 2016) in ecosystem respiration-responses that are tied to soil water availability (Pendall et al., 2013), species composition (Niu et al., 2013), and differential responses of the components of ecosystem respiration (Chen et al., 2016).

Warming can also affect ecosystem $\mathrm{C}$ uptake not only directly by changing plant photosynthesis (Luo, 2007), but also indirectly via changing the length of growing season (Sherry et al., 2007; Piao et al., 2007), soil nitrogen mineralization (Melillo et al., 2002), soil water availability (Wan et al., 2002), and species composition (Niu et al., 2013). The roles of plant phenology in ecosystem functions, especially on productivity or carbon fluxes, have received increasing attention in recent years (Han et al., 2015). For example, the length of a $\mathrm{CO}_{2}$ uptake period, or growing season length (GSL), is suggested to have significant direct effects on vegetation dynamics, carbon gains and losses (Wan et al., 2005; Piao et al., 2007; Richardson et al., 2009; Xia et al., 2013, 2015).

Globally, warming often leads to earlier flowering in spring and later senescence in autumn (Parmesan and Yohe, 2003; Root et al., 2003), indicating an extended period of active plant growth under warmer conditions. The extension of growing season may serve as one of the 
important mechanisms in enhancing ecosystem production under climate warming (Nemani et al., 2003). For example, some studies have revealed a positive dependence of net primary production (NPP) upon growing season length over the past decades (Churkina et al., 2005; Piao et al., 2007). However, the positive impact of prolonged growing season on NPP has been challenged in recent years because other processes under climate warming can counteract or reverse the positive impacts of warming-shifted plant phenology on ecosystem C uptake (Xia et al., 2013). For example, although earlier flowering improves plant fitness, summer drought associated with climate warming can reduce reproductive success of plant species (Giménez-Benavides et al., 2007) and potentially cancel out the $C$ uptake of terrestrial ecosystem (Angert et al., 2005). In addition, the enhanced respiration by autumn warming can weaken the $\mathrm{CO}_{2}$ uptake enhancement induced by earlier growing season under spring warming (Piao et al., 2008). Moreover, advanced budbreak under warming may lead to injury from late-spring frost and longer leaf retention and increase the risk of freezing damage in the autumn (Norby et al., 2003). All these studies suggest that the mechanism of warming effects on plant growth and terrestrial NPP is complex and that the influences of lengthening growing season on ecosystem $\mathrm{C}$ sequestration may be regulated by other biotic and abiotic factors associated with climate warming (Xia et al., 2013).

Plant phenology is strongly influenced by warming in alpine and Arctic ecosystems. Warming can have divergent consequences on plant phenology, including advanced (Dunne et al., 2003; Cleland et al., 2006), delayed (Hollister et al., 2005; Yu et al., 2010) or unchanged (Hoffmann et al., 2010) phenological events. By shifting phenological stages, warming can significantly extend or shorten the length of growing season which may lead to differential responses of how ecosystem carbon exchange to climate warming. To enhance our understanding of warming-shifted plant phenology influences ecosystem C cycling, we conducted a field experiment to investigate the effects of warming on phenology and ecosystem $\mathrm{C}$ exchange in a semiarid alpine meadow on the Tibetan Plateau since 2014. Three major questions were addressed: (i) How does warming influence the phenology and growing season length? (ii) What are the impacts warming-shifted plant phenology on ecosystem $\mathrm{C}$ exchange? (iii) What are the mechanisms underlying the above two processes?

\section{Material and methods}


The study area was located in a typical alpine meadow grassland at Naqu, northern Tibet, China $\left(31^{\circ} 38.513^{\prime} \mathrm{N}, 92^{\circ} 0.921^{\prime} \mathrm{E}\right)$, approximately $4600 \mathrm{~m}$ in elevation. The mean annual temperature is $-1.2^{\circ} \mathrm{C}$. The mean annual precipitation is $430 \mathrm{~mm}$, with precipitation occurring mainly during the summer season from June to September. The Asian monsoon is the main source of precipitation in this region (Dorji et al., 2013). The onset of the summer monsoon over the past nearly 60 years has a mean date of 22 May (DOY: 142 \pm 14 ), however, there is considerable annual variation. Winter precipitation, which typically falls as snow, is low in this region (Dorji et al., 2013). The growing season normally starts in mid-May and lasts until mid-September. The vegetation is dominated by Kobresia pygmaea, accompanied by Potentilla saundersiana, Potentilla cuneata, Stipa purpurea, and Festuca coelestis.

Study design

Beginning in 2014, open-top chambers ( $2.0 \mathrm{~m}$ high and $1.5 \mathrm{~m}$ along the bottom edge) were used to evaluate the effects of warming on the alpine meadow ecosystem, with three replicate chambers for both the control and warming plots. In the warming plots, chambers were placed before growth started in early April, and removed at the end of the growing season in October. In the control plots, open chambers without transparent plastic sheet were placed and removed in the same way. Soil temperature and moisture at $5 \mathrm{~cm}$ belowground were monitored with the Decagon EC-TM sensors (Decagon Devices, Pullman, Washington, USA). Measurements were taken every 1 hour for all sensors.

\section{Ecosystem C fluxes measurements}

Ecosystem C fluxes were measured in a subplot in each plot from May to September in 2014 and 2015. In each subplot, one square aluminum frame $\left(0.5 \times 0.5 \mathrm{~m}^{2}\right)$ was permanently inserted into the soil at $4 \mathrm{~cm}$ depth. Each side of the frame was $2 \mathrm{~cm}$ wide and provided a flat base between the soil surface and the $\mathrm{CO}_{2}$ sampling chamber (the chamber refitted by Niu et al., 2010). Ecosystem C exchange was measured with an infrared gas analyzer (IRGA; LI-6400, LiCor Inc., Lincoln, Nebraska, USA) attached to a transparent chamber $\left(0.5 \times 0.5 \times 0.5 \mathrm{~m}^{3}\right)$, which covered all the vegetation within the aluminum frame. The radiation is reduced by $10 \%$ within the chamber, which was measured by a Licor sensor (Licor-2003S). One small electric fan was running continuously to promote air mixing within the chamber during the measurement.

Thirty consecutive recordings of $\mathrm{CO}_{2}$ concentration were taken from each frame at 3-s 
intervals during a 90-s period after steady-state conditions were achieved within the chamber. During measurement, $\mathrm{CO}_{2}$ concentration was allowed to build up or draw down over time, from which flux rates were determined from the time-course of the concentration to calculate net ecosystem production (NEP). Increases in air temperatures within the chamber during the measuring time period were about $0.5^{\circ} \mathrm{C}$. Details about these static-chamber flux calculations can be found in the soil-flux calculation procedure on the LI-6400 manual (LiCor Inc., 2004). Following measurement of NEP, the chamber was vented, replaced on each frame, and covered with an opaque cloth. Then the $\mathrm{CO}_{2}$ exchange measurements were repeated. Because the second set of measurements eliminated light (and hence photosynthesis), the values obtained represented ecosystem respiration (ER). The difference between NEP and ER was considered to represent instantaneous GPP for the vegetation within the chamber. Measurements of ecosystem gas exchange were made twice each month at 9 am- 12 pm in 2014. In 2015, ecosystem gas exchange was measured at 5-day intervals at 9:00-12:00 am.

\section{Phenological observations}

There were 10 plant species present in the experimental plot from 2014 to 2015 . We monitored the green-up and browning phenology of five species over the entire growing season from 2014 to 2015. The five species include a dominate forb species (K. pygmaea), two forbs (P. saundersiana and P. cuneata), and two grasses (S. purpurea and Festuca coelestis), whose coverage and biomass account for more than $90 \%$ of the community. Based on their morphological traits, we classified K. pygmaea, $P$. saundersiana and $P$. cuneata as shallow-rooted species $(10 \mathrm{~cm}$ depth), and $S$. purpurea and $F$. coelestis as deep-rooted species $(30 \mathrm{~cm}$ depth). Because these five species are the dominant species in the experimental plots, we used their responses to represent the total community dynamics.

Eight individuals of $K$. pygmaea and five individuals of other species were selected from each plot and marked using a color-coded tag in May 2014. The phenology of each selected individual was scored every 3-5 days using the scoring method modified from Dunne et al. (2003) and Xia et al. (2013). For forbs, we recorded ' 0 ' for sprout-out leaf, ' 1 ' for unopened buds, ' 2 ' for opened flowers, ' 3 ' for old flowers, '4' for initiated fruits, ' 5 ' for enlarged fruits, ' 6 ' for dehisced fruits and ' 7 ' for withered plants. For grasses, we recorded ' 0 ' for sprout-out leaf, ' 0.5 ' for plant booting stage, ' 1 ' for the presence of spikelets, '2' for exerted anthers or styles, ' 3 ' for past the 
presence of anther and styles, '4' for disarticulated florets and ' 5 ' for withered plants.

\section{Data analysis}

As the Richards equation is more flexible than the logistic equation to describe different shapes of growth data (Richards, 1959), we used it with the contraction-expansion algorithm (Gu et al., 1998) to fit phenological data from each species in each plot. The equation was described as:

$$
Y=\frac{K}{\left(1+a e^{-b X}\right)^{m}}
$$

Where $Y$ is the scored phenological stages $(0-7$ for forbs and grasses for $0-5) . K$ is the maximum growth (here the last phenological stage, 7 for forbs and grasses for 5); $a$ is a parameter related to the first observation date; $b$ is growth rate (phenological stage change per day) over time $X$ (days since the first observation date); and $m$ is a parameter related to the curve shape. We estimated the 4 parameters by the contraction-expansion algorithm ( $\mathrm{Gu}$ et al., 1998). The method searches for optimal parameters by contracting and expanding search space alternatively with the objective of minimizing residual sum squares (Xia et al., 2013). The parameter estimations were performed separately for each plot and species.

Times of the green-up time (stage 0 for all species) and the browning time (stage 7 for forbs and 5 for grasses) were calculated by the calibrated Richards equation for each species in each plot. The length of growing season for each species was expressed as the time between stage 0 and stage 7 (for forbs) or stage 5 (for grasses).

In order to evaluate effects of warming on ecosystem $\mathrm{C}$ fluxes at different stages of growing season, we divided the total growing season into two periods, including early growing season (DOY: 150-200) and late growing season (DOY: 200-250) in 2014 and 2015. A repeated-measures (RM) ANOVA was used to examine warming (between-subject factor), measurement time (within-subject factor) and their interactions effects on ecosystem $\mathrm{C}$ fluxes in our study. RM-ANOVA were also used to examine warming (between-subject factor), open-top chambers (OTC), year (within-subject factor) and their interactions on the timing of green-up, browning, and the growing season length. The effects were considered to be significant if $P<0.05$. The fitting of calibrated Richards equation was carried out in Matlab (Mathworks, Natick, MA) and all statistical analyses were performed using SPSS 19.0 for Windows (SPSS Inc., Chicago, Illinois, USA). 


\section{Results}

\section{Responses of microclimate}

Precipitation amounts in the two years under investigation differed substantially; the total was 466 $\mathrm{mm}$ during the 2014 growing season (1 May to 31 September, 14\% above the long-term mean, $408 \mathrm{~mm}$ ); for 2015, it was $306 \mathrm{~mm}$ (strong drought conditions, 25\% below the long-term mean) (Fig. 1c, d). Mean daily soil temperature at $5 \mathrm{~cm}$ below-ground and air temperature at $10 \mathrm{~cm}$ above-ground were $1.7{ }^{\circ} \mathrm{C}$ and $2.2{ }^{\circ} \mathrm{C}$ higher in warmed plots than the control plots, respectively, during the 2014 growing season (Fig. 1a). In 2015, mean daily soil and air temperature were, respectively, $2.0{ }^{\circ} \mathrm{C}$ and $2.4{ }^{\circ} \mathrm{C}$ higher in the warmed plots than the control plots (Fig. 1b). Warming reduced mean daily soil moisture at $5 \mathrm{~cm}$ below-ground by $3.7 \%$ and $4.2 \%$ in 2014 and 2015, respectively (Fig. 1c, d). Soil moisture in all plots decreased between July 5 (DOY: 186) and August 8 (DOY: 220) due to drought events in 2015 (Fig. 1d).

\section{Responses of plant phenology}

The results of RM-ANOVAs showed that there were significant main effects of warming and year on the phenology events of most species $(P<0.1)$, whereas no effects of OTC on the phenology events was detected $(P>0.1)$. Few interactive effects of warming, year, and OTC on the phenology events were observed. Warming significantly delayed the green-up time of all five species $(P<0.01$ or 0.1$)$. In particular, warming delayed the green-up time by 7.5 days in $K$. pygmaea. Averaged over the five species, warming delayed the green-up time by 3.6 days (Fig. 2a; Table S1). Warming significantly delayed the browning time of $S$. purpurea by 0.9 days $(P<0.05)$, whereas no effect of warming on browning times of other four species $(P>0.1)$ was detected (Fig. 2b; Table S2). Warming significantly shortened the growth season length in $K$. pygmaea, $P$. saundersiana, and $P$. cuneata $(P<0.01)$, whereas no effects of warming on the growth season length in $S$. purpurea and $F$. coelestis $(P>0.1)$ was detected. Warming shortened the growth season length by 5.0 days averaged over the three species (Fig. 2c; Table S3).

\section{Responses of ecosystem carbon fluxes during the total growing season}

Warming had no significant effects on gross primary production (GPP) and net ecosystem production (NEP) in both 2014 and 2015 (Table 1). Warming significantly stimulated ecosystem respiration (ER) in 2015 ( $P<0.05$; Table 1), but had no effects in 2014 (Table 1). In 2015, ER was significantly increased by about $35 \%$ compared with the control $(P<0.05)$. The effects of 
measurement time (T) were significant for NEP, ER, and GPP in both years $(P<0.01$; Table 1$)$. There were significant interactions between T and warming on NEP, ER, and GPP in both years $(P<0.01 ;$ Table 1$)$.

\section{Responses of ecosystem carbon fluxes during the early and late growing season}

In whole, warming caused a seasonal shift of GPP and NEP, but not ER (Fig. 3). In 2014, warming significantly suppressed GPP and NEP during the early growing season (DOY: 150-200) $(P<0.05$; Fig. 3a, e; Table 2), but significantly stimulated GPP and NEP during the late growing season (DOY: 200-250) ( $P<0.1$ or 0.05; Fig. 3a, e; Table 2). On average, GPP and NEP were suppressed by $45 \%$ and $61 \%$ during the early growing season, and stimulated by $28 \%$ and $45 \%$ during the late growing season, respectively (Fig. 3a, e). Warming had no significant effects on ER at either early or late growing season in 2014 (Fig. 3c; Table 2).

In 2015, warming significantly stimulated ER ( $P<0.1$ or 0.01 ; Fig. $3 \mathrm{~d}$ ), but had no effects on NEP at either early or late growing season (Fig. 3b; Table 2). ER was stimulated by $26 \%$ and $44 \%$ during the early and late growing season, respectively (Fig. 3d). Warming had no effects on GPP during the early growing season, but significantly stimulated GPP during the late growing season $(P<0.1$; Fig. 3f; Table 2). GPP was stimulated by 33\% during the late growing season in 2015 (Fig. 3f).

\section{Discussion}

\section{The effects of warming on plant phenology}

The alpine ecosystem on the Tibetan Plateau is a highly water constrained ecosystem due to its high evaporation. Under these highly water constrained conditions, warming would further accelerate the dry conditions (Valpine and Harte, 2001; Rutishauser et al., 2012; Dorji et al., 2013), resulting in delayed plant phenology (Hollister et al., 2005; Yu et al., 2010). Warming did not significantly affect the browning times in most species. This is not consistent with recent experimental efforts and modeling observations suggesting that warming delays the timing of leaf senescence or autumn phenology (Gunderson et al., 2012; Marchin et al., 2015; Liu et al., 2016). On the one hand, warming could constrain plant growth and photosynthesis activity (Tezara et al., 1999), and increase the risk of chlorophyll degradation and plant mortality (Anderegg et al., 2013), subsequently resulting in earlier autumn phenology. On the other hand, warming delayed spring phenology (Zhu et al., 2016), and a later spring is often associated with a later autumn senescence 
(Keenan and Richardson, 2015). Probably because of these two reasons, the timing of autumn senescence was not affected by warming in our semiarid study area.

Our results are also in contrast to previous studies showing that warming often leads to earlier flowering in spring and later senescence in autumn (Parmesan and Yohe, 2003; Root et al., 2003), indicating an extended period of active plant growth under warmer conditions. In our study system, warming led to later green-up in spring phenology and little change in autumn phenology. Therefore, warming significantly shortened the length of growing season, particularly in shallow-rooted species. Under warming, the length of growing season was shortened by 5.0 days averaged over the three shallow-rooted species. Warming did not significantly change the growing season length for the two deep-rooted species, S. purpurea and F. coelestis.

\section{Seasonal shift of ecosystem C exchange}

Our results provide strong evidence that warming drives a seasonal shift of ecosystem carbon exchange in the Tibetan alpine meadow. The effect of warming-shifted plant phenology on ecosystem C uptake has received increasing attention in recent years (Xia et al., 2013, 2015; Han et al., 2015). In our study, warming delayed plants growth and phenological development during the early growing season. Correspondingly, warming suppressed GPP and NEP during the early growing season. However, warming accelerated plants growth and $\mathrm{C}$ uptake under ample water conditions during the late growing season. Therefore, warming stimulated GPP and NEP during the late growing season. In addition, this seasonal shift induced by warming were modulated by water availability. For example, in the dry growing season of 2015, warming had no significant effects on GPP due to water limitation during the early growing season.

The extension of growing season induced by warming may serve as one of the important mechanisms in enhancing ecosystem production under climate warming (Nemani et al., 2003; Churkina et al., 2005; Piao et al., 2007). However, climate warming does not always extend the length of growing season. In our study system, warming led to later green-up in spring and little change in autumn phenology, shortening the growing season. Under warming conditions, the length of growing season was shortened by 5.0 days averaged over the three shallow-rooted species. The shortened growing season is translated into a shorter $\mathrm{CO}_{2}$ uptake period, which may weaken ecosystem C sequestration (Churkina et al., 2005; Piao et al., 2007). However, warming had no significant effects on GPP and NEP in both wet and dry years. The positive impact of 
prolonged growing season on ecosystem $\mathrm{C}$ uptake has been challenged in recent years, because other processes under climate warming can counteract or reverse the positive impacts of warming-shifted plant phenology on ecosystem C uptake (Xia et al., 2013). In our study, warming caused a seasonal shift of GPP and NEP, where the stimulation of ecosystem C fluxes in late growing season counteracted the suppression of ecosystem C fluxes in early growing season induced by warming. Therefore, our results suggest that a positive dependence of ecosystem carbon sequestration upon growing season length seen in some ecoregions may not necessarily apply to other ecosystems.

\section{The effects of warming on ecosystem respiration}

Responses of ecosystem respiration (ER) to warming in individual studies have been highly variable (Chen et al., 2016). For example, warming could significantly increase (Niu et al 2013), decrease (Fu et al., 2013; Pendall et al., 2013) or have little effects (Xia et al., 2009; Chen et al., 2016) on ecosystem respiration. These responses have been attributed to changes of soil water availability (Pendall et al., 2013), species composition (Niu et al., 2013), and differential responses of ecosystem respiration components to warming (Chen et al., 2016). Our study showed that warming stimulated ecosystem $\mathrm{C}$ release during the dry growing season of 2015 , whereas there were no significant effects on C release during the wet growing season of 2014. Our results are in contrast to previous studies reporting that warming increases ecosystem $\mathrm{C}$ release ( $\mathrm{Lu}$ et al., 2013; Wang et al., 2014). The differential responses of ecosystem respiration components to warming, such as increase in above-ground plant respiration and decrease in heterotrophic respiration (Chen et al., 2016), may have resulted in the lack of responses of ecosystem respiration in 2014. It has been proposed that warming effects on ecosystem respiration are likely modulated by soil water regimes (Parton et al., 2012; Pendall et al., 2013). Precipitation is known to strongly stimulate soil respiration (Birch, 1958; Norton et al., 2008), particularly in arid and semi-arid regions (Sponseller, 2007); some studies have shown that the lower soil moisture content was, the stronger stimulating effects were (Liu et al., 2002). During the dry growing season of 2015, the precipitation events could significantly stimulate ecosystem respiration in the warming treatments (Table S4), which resulted in the significant responses of ecosystem respiration in 2015.

By conducting a warming experiment in an alpine grassland over two growing seasons, we show that warming caused delayed green-up in the spring but little change in autumn 
senescence. However, the altered phenology did not translate into changes in total seasonal C fluxes, because decreases in NEP and GPP in the first half of the season and increases in NEP and GPP in second half of the season counteracted each other in the wet year, and warming increased ecosystem respiration but not NEP in the dry year. The contrasting results with previous work point to the context dependency of species and ecosystem responses to warming, emphasizing the need to investigate the ecological consequence of climate warming in a wide variety of ecosystems.

\section{Acknowledgements}

We are grateful to Dr. Yaojie Liu and Ning Chen for their help in field measurements. This project is supported by the 973 Programme of the Ministry of Science and Technology of China (2013CB956302); the youth innovation team project of Key Laboratory of Ecosystem Network Observation and Modeling (LENOM2016Q0002) and National Natural Science Foundation of China (41571195); West Light Foundation of the Chinese Academy of Sciences; the Construction Service Programme for Cultivating Unique Institute of the Chinese Academy of Sciences (TSYSJ05) and State Key Laboratory of Resources and Environmental Information System. LJ is supported by National Science Foundation of the USA (DEB-1257858 and DEB-1342754) and National Natural Science Foundation of China (31361123001).

Competing interests. The authors declare that they have no conflict of interest.

\section{Reference}

1. Anderegg, W.R., et al., 2013. Drought's legacy: multiyear hydraulic deterioration underlies widespread aspen forest die-off and portends increased future risk. Global Change Biol. 19, $1188-1196$.

2. Angert, A. et al., 2005. Drier summers cancel out the $\mathrm{CO}_{2}$ uptake enhancement induced by warmer springs. P. Natl. Acad. Sci. USA. 102, 10823-10827.

3. Birch, H.F., 1958. The effect of soil drying on humus decomposition and nitrogen availability. Plant Soil 10, 9-31.

4. Brient, F., Bony, S., 2013. Interpretation of the positive low-cloud feedback predicted by a 
climate model under global warming. Clim. Dyn. 40, 2415-2431.

5. Charrier, G., Améglio, T., 2011. The timing of leaf fall affects cold acclimation by interactions with air temperature through water and carbohydrate contents. Environ. Exp. Bot., 72, 351-357.

6. Chen, J., et al., 2016. Differential responses of ecosystem respiration components to experimental warming in a meadow grassland on the Tibetan Plateau. Agric. Forest Meteorol. $220,21-29$.

7. Churkina, G., Schimel, D., Braswell, B.H., Xiao, X., 2005. Spatial analysis of growing season length control over net ecosystem exchange. Global Change Biol. 11, 1777-1787.

8. Cleland, E.E., Chiariello, N.R., Loarie, S.R., Mooney, H.A., Field, C.B., 2006. Diverse responses of phenology to global changes in a grassland ecosystem. P. Natl. Acad. Sci. USA. 103, 13740-13744.

9. Dai, A., Trenberth, K.E., Qian, T., 2004. A global dataset of Palmer Drought Severity Index for 1870-2002: Relationship with soil moisture and effects of surface warming. J. Hydrometeorol. 5, 1117-1130.

10. Dorji, T., et al., 2013. Plant functional traits mediate reproductive phenology and success in response to experimental warming and snow addition in Tibet. Global Change Biol. 19, $459-472$.

11. Dunne, J.A., Harte, J., Taylor, K.J., 2003. Subalpine meadow flowering phenology responses to climate change: Integrating experimental and gradient methods. Ecol. Monogr. 73, 69-86.

12. Friedlingstein, P. et al., 2006. Climate-carbon cycle feedback analysis: results from the C4MIP model intercomparison. J. Climate. 19, 3337-3353.

13. Fu, G., et al., 2013. Experimental warming does not enhance gross primary production and above-ground biomass in the alpine meadow of Tibet. J. Appl. Remote Sens. 7, 6451-6465.

14. Gunderson, C.A., et al., 2012. Forest phenology and a warmer climate-growing season extension in relation to climatic provenance. Global Change Biol. 18, 2008-2025.

15. Gu. S., Hui, D., Bian, A., 1998. The contraction-expansion algorithm and its usein fitting nonlinear equations. J. Biomath. 13, 426-434.

16. Han, J.J., Chen, J.Q., Xia, J.Y., Li, L.H., 2015. Grazing and watering alter plant phenological processes in a desert steppe community. Plant Ecol. 216, 599-613. 
17. Hoffmann, A.A., et al., 2010. Phenological changes in six Australian subalpine plants in response to experimental warming and year-to-year variation. J. Ecol. 98, 927-937.

18. Hollister, R.D., Webber, P.J., Bay, C., 2005. Plant response to temperature in northern Alaska: Implications for predicting vegetation change. Ecology 86, 1562-1570.

19. IPCC (2007) Summary for policymakers. In: Climate change 2007: The physical acience basis. contribution of working group I to the fourth assessment report of the intergovernmental panel on climate change. (eds Solomon S, Qin D, Manning M, Chen Z, Marquis M, Averyt KB, Tignor M, Miller HL) pp 1-18. Cambridge University Press, Cambridge, United Kingdom.

20. IPCC, 2014. Climate Change 2013: The Physical Science Basis: Working Group I Contribution to the Fifth Assessment Report of the Intergovernmental Panel on Climate Change. Cambridge University Press.

21. Keenan, T.F., Richardson, A.D., 2015. The timing of autumn senescence is affected by the timing of spring phenology: implications for predictive models. Global Change Biol. 4, 87-93.

22. Liu, Q. et al., 2016. Delayed autumn phenology in the northern hemisphere is related to change in both climate and spring phenology Global Change Biol. doi: 10.1111/gcb.13311.

23. Liu, X., Chen, B., 2000. Climatic warming in Tibetan Plateau during recent decades. Int. J. Climatol. 20, 1729-1742.

24. Liu, X., Wan, S., Su, B., Hui, D., Luo, Y., 2002. Responses of soil $\mathrm{CO}_{2}$ efflux to water manipulation in a tallgrass prairie ecosystem. Plant and Soil 240, 213-223.

25. Lu, M., Zhou, X., Yang, Q., Li, B., 2013. Responses of ecosystem carbon cycle to experimental warming: a meta-analysis. Ecology 94, 726-738.

26. Luo, Y., 2007. Terrestrial carbon-cycle feedback to climate warming. Annu. Rev. Ecol. Evol. $38,683-712$.

27. Marchin, R.M., Salk, C.F., Hoffmann, W.A., Dunn, R.R., 2015. Temperature alone does not explain phenological variation of diverse temperate plants under experimental warming Global Change Biol. 21, 3138-3151.

28. Melillo, J.M., Morrisseau, S., 2002. Soil warming and carbon cycle feedbacks to the climate systems. Science 298, 2173-2176. 
29. Nemani, R.R., et al., 2003. Climate-driven increases in global terrestrial net primary production from 1982 to 1999 . Science $300,1560-1563$.

30. Niu, S.L, Sherry, R.A., Zhou, X.H., Wan, S.Q., Luo, Y.Q., 2010. Nitrogen regulation of the climate-carbon feedback: evidence from a long-term global change experiment. Ecology 91, $3261-3273$.

31. Niu, S.L., Sherry, R.A., Zhou, X.H., Luo, Y.Q., 2013. Ecosystem carbon fluxes in response to warming and clipping in a Tallgrass Prairie. Ecosystems 16, 948-961.

32. Norby, R.J., Hartz-Rubin, J.S., Verbrugge, M.J., 2003. Phenological responses in maple to experimental atmospheric warming and $\mathrm{CO}_{2}$ enrichment Global Change Biol. 9, 1792-1801.

33. Norton, U., Mosier, A.R., Morgan, J.A., Derner, J.D., Ingram, L.J., Stah, P.D., 2008. Moisture pulses, trace gas emissions and soil $\mathrm{C}$ and $\mathrm{N}$ in cheatgrass and native grass-dominated sagebrush-steppe in Wyoming, USA. Soil Biol. Biochem. 40, 1421-1431.

34. Parmesan, C., Yohe, G., 2003. A globally coherent fingerprint of climate change impacts across natural systems. Nature 421, 37- 42 .

35. Parton, W., et al., 2012. Impact of precipitation dynamics on net ecosystem productivity Global Change Biol. 18, 915-927.

36. Pendall, E., et al., 2013. Warming reduces carbon losses from grassland exposed to elevated atmospheric carbon dioxide. Plos One 8e71921.

37. Piao, S.L., et al., 2008. Net carbon dioxide losses of northern ecosystems in response to autumn warming. Nature 451, 49-52.

38. Piao, SL., et al., 2007. Growing season extension and its effects on terrestrial carbon flux over the last two decades. Global Biogeochem. Cycles. 21, 1148-1154.

39. Richardson, A.D., et al., 2009. Influence of spring phenology on seasonal and annual carbon balance in two contrasting New England forests. Tree Physiol. 29, 321-331.

40. Root, T.L., et al., 2003. Fingerprints of global warming on wild animals and plants. Nature $421,57-60$.

41. Rutishauser, T., Stockli, R., Harte, J., Kueppers, L., 2012. Climate change: flowering in the greenhouse. Nature 485, 448-449.

42. Sherry, R.A., et al., 2007. Divergence of reproductive phenology under climate warming Proc. Nat. Acad. Sci. USA . 104, 198-202. 
43. Sponseller RA (2007). Precipitation pulses and soil CO2 flux in a Sonoran Desert ecosystem. Global Change Biol. 13, 426-436.

44. Tezara, W., Mitchell, V., Driscoll, S., Lawlor, D., 1999. Water stress inhibits plant photosynthesis by decreasing coupling factor and ATP. Nature 401, 914-917.

45. Valpine, P.D., Harte. J., 2001. Plant responses to experimental warming in a montane meadow Ecology 82, 637-648.

46. Wan, S., Hui, D., Wallace, L., Luo, Y., 2005. Direct and indirect effects of experimental warming on ecosystem carbon processes in a tallgrass prairie Global Biogeochem. Cycles. 19, GB2014, doi:10.1029/2004GB002315.

47. Wan, S., Luo, Y., Wallace, L., 2002. Changes in microclimate induced by experimental warming and clipping in tallgrass prairie. Global Change Biol. 8, 754-768.

48. Wang, X., et al., 2014. Soil respiration under climate warming: differential response of heterotrophic and autotrophic respiration Global Change Biol. 20, 3229-3237.

49. Xia, J.Y., et al., 2015. Joint control of terrestrial gross primary productivity by plant phenology and physiology. P. Natl. Acad. Sci. USA. 112, 2788-2793.

50. Xia, J.Y., Niu, S.L., Wan, S.Q., 2009. Response of ecosystem carbon exchange to warming and nitrogen addition during two hydrologically contrasting growing seasons in a temperate steppe. Global Change Biol. 15, 1544-1556.

51. Xia, J.Y., Wan, S.Q., 2013. Independent effects of warming and nitrogen addition on plant phenology in the Inner Mongolian steppe. Ann. Bot. 111, 1207-1217.

52. Yu, H., Luedeling, E., Xu, J., 2010. Winter and spring warming result in delayed spring phenology on the Tibetan Plateau. P. Natl. Acad. Sci. USA. 107, 22151-22156.

53. Zhu, J.T., Zhang, Y.J., Wang, W.F., 2016. Interactions between warming and soil moisture increase overlap in reproductive phenology among species in an alpine meadow. Biol. Lett. 12, 20150749. 
1 Table 1 Results ( $F$ Values) of repeated-measurement ANOVA on the effects of experimental

2 warming, measurement time (T) and their interactions on net ecosystem production (NEP),

3 ecosystem respiration (ER), and gross primary production (GPP).

\begin{tabular}{|c|c|c|c|c|c|c|}
\hline \multirow[t]{2}{*}{ Source } & \multicolumn{3}{|c|}{2014} & \multicolumn{3}{|c|}{2015} \\
\hline & NEP/DF & ER/DF & GPP/DF & NEP/DF & ER/DF & GPP/DF \\
\hline Warming & $0.22 / 1$ & $0.18 / 1$ & $0.05 / 1$ & $0.02 / 1$ & $17.12 / 1^{* *}$ & $1.04 / 1$ \\
\hline $\mathbf{T}$ & $8.18 / 7^{* * *}$ & $21.08 / 7^{* * *}$ & $16.59 / 7^{* * *}$ & $14.93 / 14^{* * *}$ & $8.59 / 14^{* * *}$ & $16.95 / 14^{\text {*** }}$ \\
\hline $\mathrm{T} \times$ warming & $2.84 / 7^{* *}$ & $8.03 / 7^{* * *}$ & $5.86 / 7^{* * *}$ & $2.63 / 14^{* * *}$ & $7.10 / 14^{* * *}$ & $3.15 / 14^{* * *}$ \\
\hline \multicolumn{7}{|c|}{ DF degree of freedom } \\
\hline
\end{tabular}

4

5

6

7

8

9

10

11

12

13

14

Table 2 Results ( $F$ Values) of repeated-measurement ANOVA on the effects of experimental warming, measurement time (T) and their interactions on net ecosystem production (NEP), ecosystem respiration (ER), and gross primary production (GPP) during early growing season (DOY: 150-200) and late growing season (DOY: 200-250) in 2014 and 2015.

\begin{tabular}{|c|c|c|c|c|c|c|}
\hline \multirow[t]{3}{*}{ Source } & \multicolumn{6}{|c|}{2014} \\
\hline & \multicolumn{3}{|c|}{ Early growing season } & \multicolumn{3}{|c|}{ Late growing season } \\
\hline & NEP/DF & ER/DF & GPP/DF & NEP/DF & ER/DF & GPP/DF \\
\hline Warming & $12.39 / 1 * *$ & $4.19 / 1$ & $8.73 / 1 * *$ & $12.46 / 1 * *$ & $0.18 / 1$ & $5.39 / 1 *$ \\
\hline $\mathbf{T}$ & $5.68 / 3^{* *}$ & $14.36 / 3^{* * *}$ & $10.65 / 3^{* * *}$ & $0.52 / 3$ & $12.39 / 3^{* * *}$ & $1.68 / 3$ \\
\hline \multirow[t]{4}{*}{$\mathbf{T} \times$ warming } & $1.11 / 3$ & $10.63 / 3^{* * *}$ & $3.74 / 3^{* *}$ & $0.99 / 3$ & $4.65 / 3^{* *}$ & $2.22 / 3$ \\
\hline & \multicolumn{6}{|c|}{2015} \\
\hline & \multicolumn{3}{|c|}{ Early growing season } & \multicolumn{3}{|c|}{ Late growing season } \\
\hline & NEP/DF & ER/DF & GPP/DF & NEP/DF & ER/DF & GPP/DF \\
\hline Warming & $2.11 / 1$ & $5.41 / 1 *$ & $0.35 / 1$ & $0.79 / 1$ & $36.32 / 1 * * *$ & $5.29 / 1 *$ \\
\hline $\mathbf{T}$ & $15.94 / 3^{* * *}$ & $4.90 / 3^{* * *}$ & $13.07 / 3^{* * *}$ & $10.45 / 3^{* * *}$ & $15.00 / 3^{* * *}$ & $19.59 / 3^{* * *}$ \\
\hline $\mathbf{T} \times$ warming & $1.32 / 3$ & $3.01 / 3^{* *}$ & $0.20 / 3$ & $1.97 / 3^{*}$ & $13.37 / 3^{* * *}$ & $4.35 / 3^{* * *}$ \\
\hline \multicolumn{7}{|c|}{$\begin{array}{l}\text { DF degree of freedom } \\
*{ }^{* * *},{ }^{* * *} \text { Significance was at the level of } P<0.1,0.05, \text { and } 0.01 \text { respectively. }\end{array}$} \\
\hline
\end{tabular}


1

2 Fig. 1 Mean daily soil temperature $\left({ }^{\circ} \mathrm{C}\right)$ at $5 \mathrm{~cm}$ depth (a, b), mean daily soil moisture (\%) at $5 \mathrm{~cm}$

$4 \quad$ warming and control (ambient) chambers.

5

6

7

8

9

10

11

12

13

14 


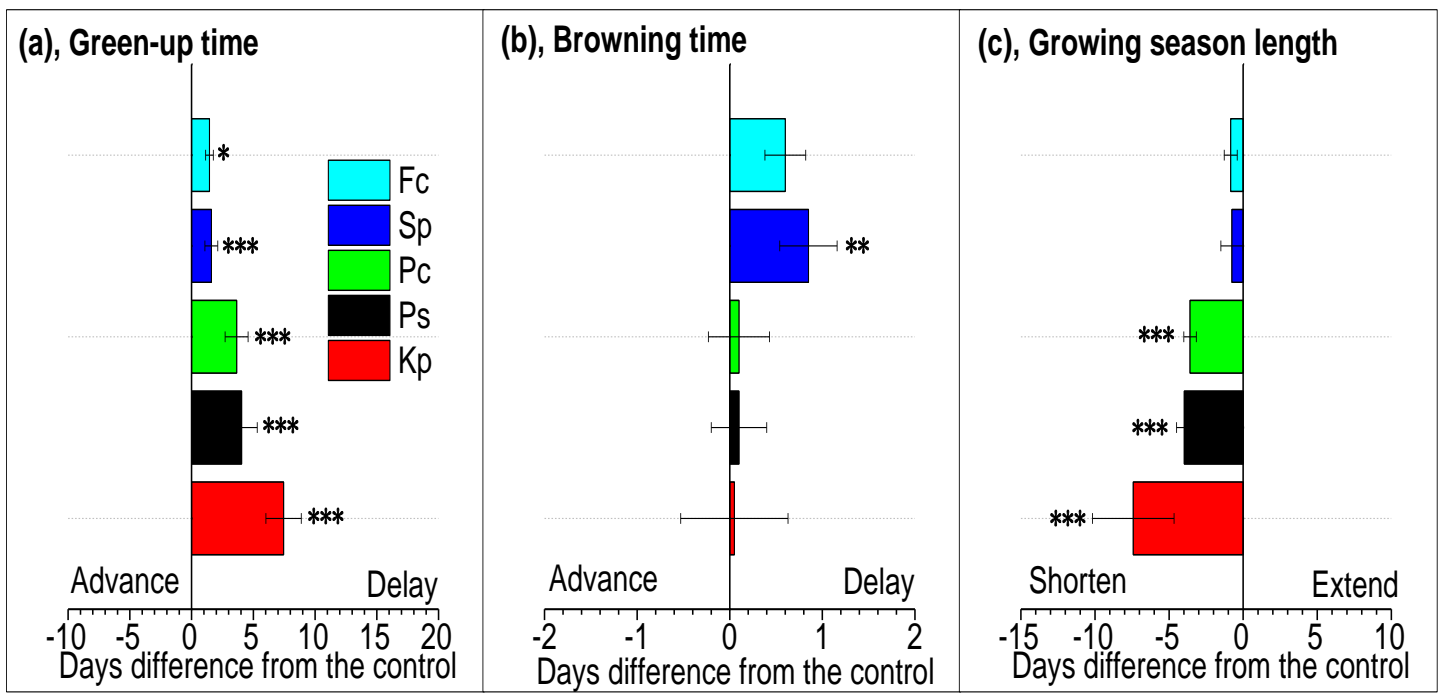

Fig.2 Changes in the green-up (in days) time (a), browning time (b), and growing season length (c, GSL) in the warming treatment compared with the control average over two years (2014 and 2015). A positive value indicates later green-up, browning time or extended GSL than the control; a negative value indicates earlier green-up, browning time or shortened GSL than the control. Data are mean $\pm \mathrm{SD} . \mathrm{Kp}, \mathrm{Ps}, \mathrm{Pc}, \mathrm{Sp}$ and Fc represent Kobresia pygmaea, Potentilla saundersiana, ***, $P<0.01$. 


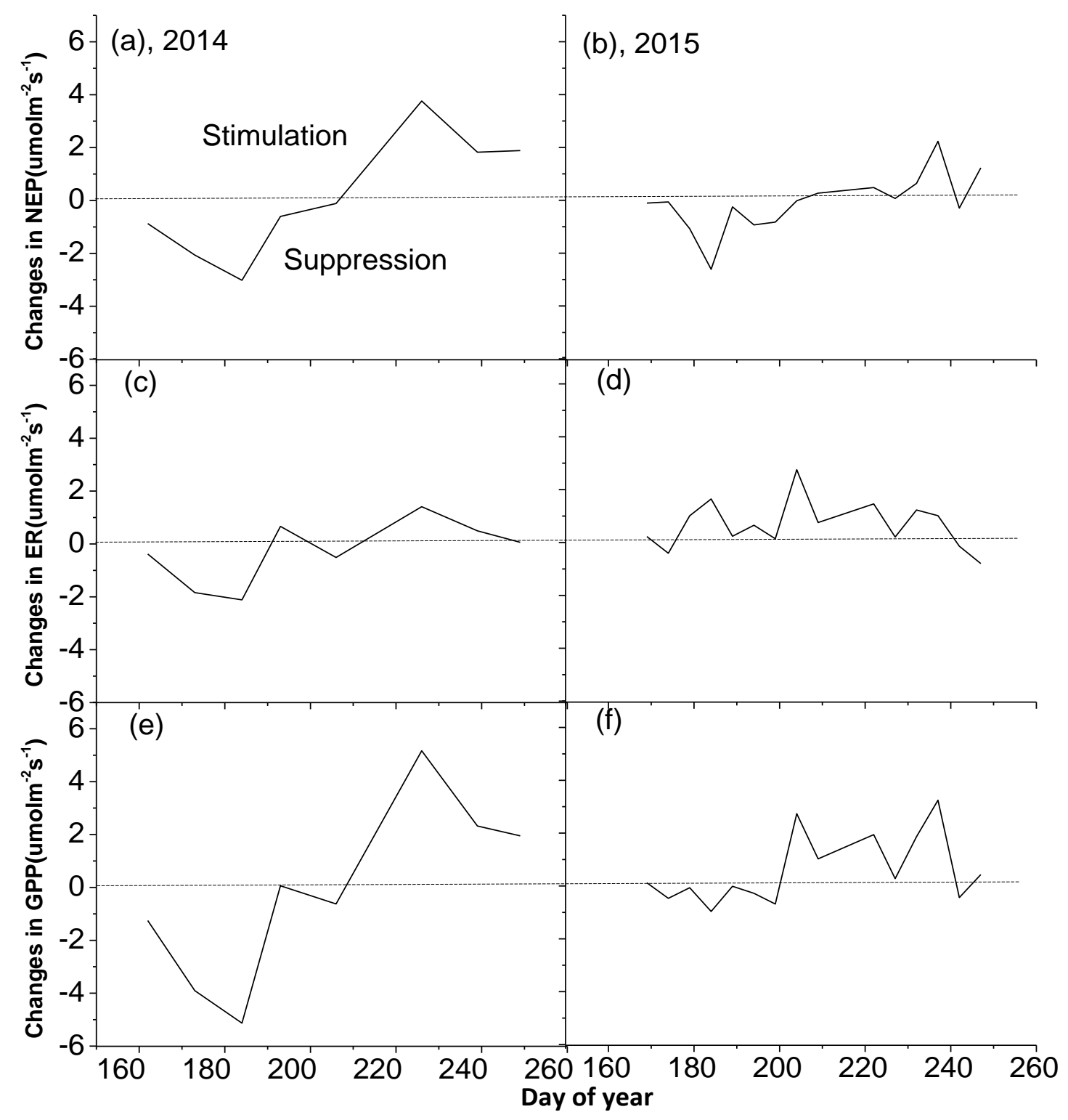

Fig.3 Seasonal patterns of warming effects on ecosystem C fluxes, including net ecosystem production (NEP, a, b), ecosystem respiration (ER, c, d), and gross primary production (GPP, e, f). Warming effects are expressed as differences from the control for each year of the experiment, with increases in C fluxes as "stimulation" and decreases in C fluxes as "suppression." 


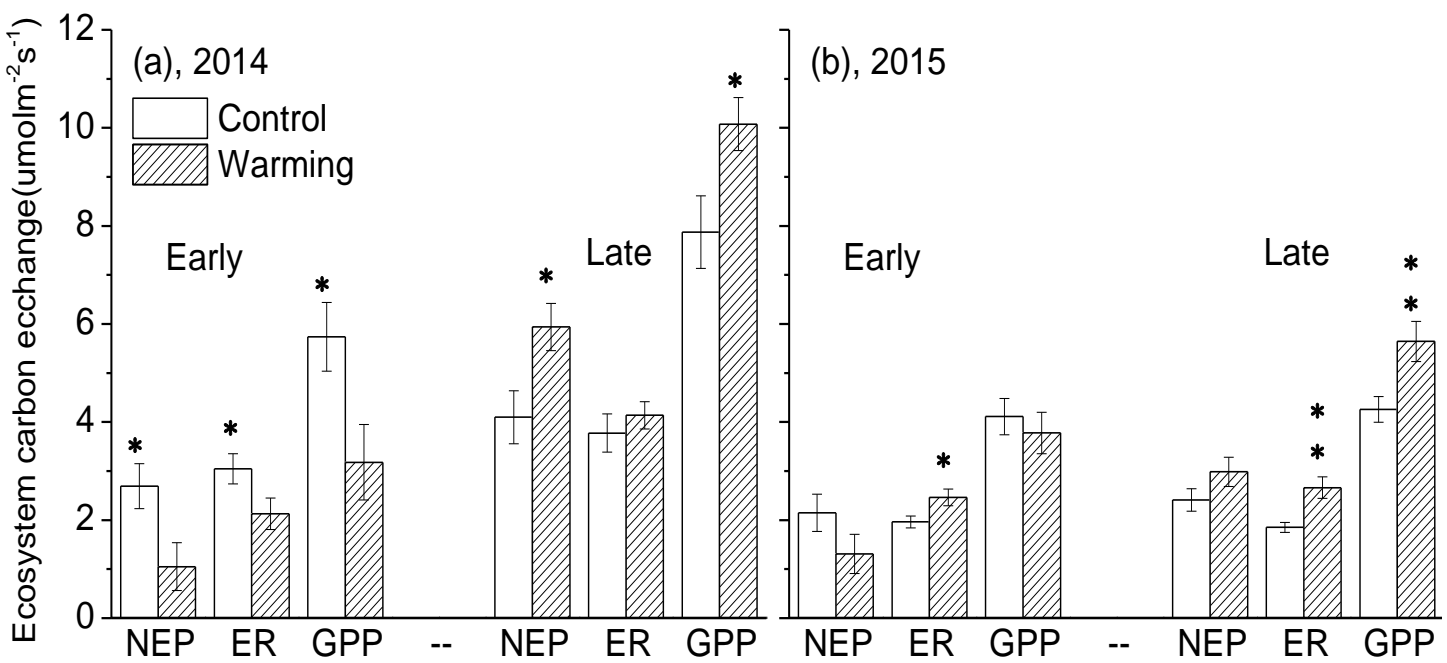

39

40

41

42

43

Fig.4 Average rates of ecosystem $\mathrm{C}$ uptake and release during the early and late growing season in 2014 (a) and 2015 (b). NEP, ER, and GPP indicate net ecosystem production, ecosystem respiration, and gross primary production, respectively. We defined the early growing season as DOY from 150 to 200, and the late growing season as DOY from 200 to $250 . *, P<0.05$; **, $P<$ 30.01 